\section{Evaluation of Substrate Hydraulic Properties Amended by Urea-formaldehyde Resin Foam}

\author{
Paraskevi A. Londra', Maria Psychoyou, and John D. Valiantzas \\ Agricultural University of Athens, Department of Natural Resources \\ Management and Agricultural Engineering, Laboratory of Agricultural \\ Hydraulics, 75 Iera Odos, Athens 11855, Greece
}

Additional index words. substrates, urea-formaldehyde resin foam, water retention curve, hydraulic conductivity, one-step outflow method

\begin{abstract}
Urea-formaldehyde resin foam has been introduced as a synthetic organic soil amendment and is used in hydroponic systems, soilless cultures, production of containergrown plants, roof gardens, and sports fields. To evaluate whether urea-formaldehyde resin foam can improve physical properties (water retention capacity and aeration) of horticultural substrates, an organic substrate (coir) and an inorganic soil (loam soil) were selected and amended with urea-formaldehyde resin foam (Fytocell). Water retention curves, $\theta(h)$, saturated hydraulic conductivity, $K_{s}$, and the relationship between unsaturated hydraulic conductivity and volumetric water content, $K(\theta)$, were determined for Fytocell, coir, loam soil, mixtures of coir/Fytocell $(60 / 40 \mathrm{v} / \mathrm{v})$, and loam soil/Fytocell $(60 / 40 \mathrm{v} / \mathrm{v})$. Water retention curves indicated that the addition of Fytocell in loam soil and coir mixtures increased and decreased, respectively, the water retention capacity. The $K_{s}$ of loam soil and coir mixtures were decreased and increased, respectively, by the addition of Fytocell. In all substrates studied, $K(\theta)$ decreased sharply when $\theta$ decreased from 0.80 to $0.20 \mathrm{~m}^{3} \cdot \mathrm{m}^{-3}$. However, the coir/Fytocell mix had the highest values of $K(\theta)$ when $\theta$ was below $0.40 \mathrm{~m}^{3} \cdot \mathrm{m}^{-3}$. Moreover, the comparison between estimated $K(\theta)$ values obtained using the experimental outflow method of Valiantzas (1989) and predicted values using the van Genuchten-Mualem model showed a satisfactory agreement $\left(0.937 \leq R^{2} \leq 0.996\right)$ for the substrates examined.
\end{abstract}

Recently, urea-formaldehyde resin foam (UFRF) has been introduced as a synthetic organic soil amendment and is used as a substrate in the propagation and growth of plants in hydroponic systems, soilless cultures, and substrates used in production of container-grown plants, in roof gardens, and sports fields. Ureaformaldehyde resin foam and its effect on plant growth has been the subject of study as an amendment for soils and organic substrates for several researchers (Chan and Joyce, 2007; Mooney and Baker, 1999; Nektarios et al., 2003, 2004; Nguyen et al., 2009; Nikolopoulou and Nektarios, 2004; Nikolopoulou et al., 2004). Urea-formaldehyde resin foam is environmentally friendly, lightweight $\left(18-30 \mathrm{~kg} \cdot \mathrm{m}^{-3}\right)$, slowly biodegradable over a period of 20 years, sterile, and has a high water retention capacity $(57 \% \mathrm{v} / \mathrm{v})$ (Werminghausen, 1972). Furthermore, UFRF has been found to increase airfilled porosity and water infiltration of fine texture soils and water retention of coarse texture soils (Baader, 1999). In this article, a UFRF with the brand name Fytocell was studied (Fig. 1). Over the past 10-year introduction period, Fytocell has provided such

Received for publication 9 May 2012. Accepted for publication 25 July 2012.

We thank the KITANTZIS group of companies for the donation of the substrates used in this study.

${ }^{1}$ To whom reprint requests should be addressed; e-mail v.londra@aua.gr. results that could characterize it as a "unique and promising" substrate for the soilless culture sector (Welleman, 2005). This compound has a spongy structure and could be used either in the form of slabs or flakes as a component of organic and inorganic mixtures.

Previous research using UFRF has mainly focused on the study of the physical properties of UFRF-amended soils and organic substrates (Chan and Joyce, 2007; Mooney and Baker, 1999; Nektarios et al., 2003, 2004; Nguyen et al., 2009). Mooney and Baker (1999) determined the $K_{s}$ of UFRF-amended sandy soils and Nektarios et al. $(2003,2004)$ determined the $\theta(h)$ of UFRF-amended soils and substrates.

However, the knowledge of both main hydraulic properties of UFRF-amended substrates such as $\theta(h)$ and the relationship between unsaturated hydraulic conductivity and volumetric water content, $K(\theta)$, is necessary for the selection of substrates for plant growth and the proper management of irrigation. Although $\theta(h)$ for substrates is easily determined in the laboratory, the direct experimental determination of $K(\theta)$ is usually difficult, time-consuming, and requires specialized laboratory equipment (Londra, 2010). Many researchers have used mathematical models to calculate $\theta(h)$ and $K(\theta)$ for substrates (Fonteno et al., 1981; Karlovich and Fonteno, 1986; Londra, 2001; Londra and Valiantzas, 2011; Milks et al., 1989; Valiantzas et al., 2007; Wallach et al., 1992). However, large fluctua- tions in hydraulic conductivity $(K)$ between different substrates limit the predictive value of these models.

An indirect experimental procedure for estimating $K(\theta)$ is the one-step outflow method. This procedure is one of the most widely used laboratory methods for determining $K(\theta)$ (if water retention data are available) and the soil water diffusivity, $D$, as a function of the volumetric water content $\theta[D(\theta)]$ on porous material samples of small height. In the onestep outflow method, a short soil or substrate sample of height $L$, with initial water content $\theta_{i}$, is suddenly subjected to a large increment of pressure and the outflow volume, $V$, is recorded with time, $t$, until the water content reaches the final equilibrium value $\theta_{f}($ Gardner, 1962; Gupta et al., 1974; Passioura, 1976; Valiantzas, 1989; Valiantzas et al., 1988, 2007).

Compared with other methods, the onestep outflow method requires little time for the calculation of $K$ but cannot be applied in the first outflow stage, in which the flow is practically determined by the resistance of the porous plate (Passioura, 1976; Valiantzas, 1990). Therefore, the method cannot be used for the calculation of $K$ near saturation.

In this study, laboratory experiments were conducted for determining the $\theta(h)$ in substrate samples of Fytocell, loam soil/Fytocell $(60 / 40 \mathrm{v} / \mathrm{v})$, coir/Fytocell $(60 / 40 \mathrm{v} / \mathrm{v})$, coir, and loam soil. In the same substrate samples under the same experimental apparatus, onestep outflow experiments were also carried out to estimate the relations of $D(\theta)$ and consequently $K(\theta)$. Therefore, the $K(\theta)$ values were compared with the values predicted by the most popular closed-form analytical hydraulic model of van Genuchten-Mualem. Furthermore, the $K_{s}$ was determined experimentally.

The main aim of this study was to evaluate the effect of UFRF on the hydraulic behavior of its mixtures with a soil and an organic substrate. Contrary to previously reported research (Chan and Joyce, 2007; Mooney and Baker, 1999; Nektarios et al., 2003, 2004; Nguyen et al., 2009), in this study, both basic hydraulic properties, the water retention curve and the relationship between unsaturated hydraulic conductivity and volumetric water content, of the UFRF and its mixtures were determined using a fast and easy methodology in the same substrate sample for a range of water contents of vital importance for the plant growth.

\section{Materials and Methods}

Substrates. The substrates studied were: 1) a UFRF (Fytocell; Resins Agro B.V., The Netherlands), which was used in the form of foam flakes both as a pure substrate and as a component of substrate mixtures; 2) coir, which is a byproduct of coconut husk fiber treatment (van der Knaap, The Netherlands). Coir has a compressed form (bricks) with dimensions $30 \mathrm{~cm} \times 30 \mathrm{~cm} \times 15 \mathrm{~cm}$ for easy transportation; 3) a loam soil composed of $50.16 \%$ sand, $33.82 \%$ silt, and $16.02 \%$ clay; 4) a mixture of loam soil and Fytocell in 


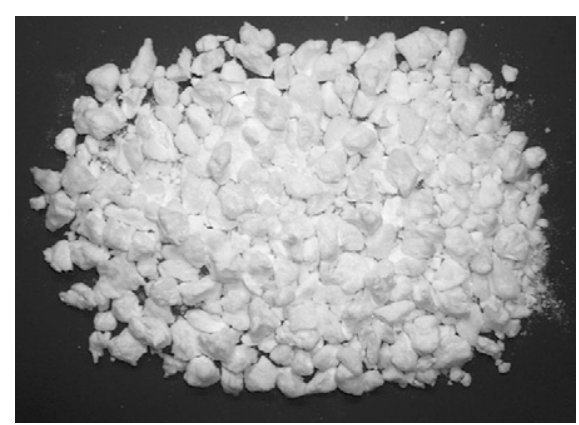

Fig. 1. Fytocell in the form of flakes.

a proportion $60 / 40 \mathrm{v} / \mathrm{v}$ loam soil/Fytocell; and 5) a mixture of coir and Fytocell in a proportion $60 / 40 \mathrm{v} / \mathrm{v}$ coir/Fytocell.

Experimental procedure. Water retention curve measurements and one-step outflow laboratory experiments were performed on a tension plate apparatus in a Haines-type assembly (Haines, 1930), in which negative pressure steps were applied through the saturated tension plate. Initially, the $\theta(h)$ were measured followed by the one-step outflow experiment in the same substrate sample in the same apparatus to avoid the effect of sample variability in the obtained results by the two experimental methods. Three replications per substrate were conducted $(n=3)$.

Water retention curves. To achieve a satisfactory packing of the substrate samples, small amounts of substrate were gradually put on the tension plate apparatus in a Hainestype assembly with simultaneous vibration of the latter. The samples were less than $3 \mathrm{~cm}$ in height and $9.2 \mathrm{~cm}$ in diameter. The air-entry value of the tension plate was $-180 \mathrm{~cm}$ of the water column. The UFRF flakes and coir were pre-wetted before using. The samples were allowed to wet gradually from the bottom of the plate until saturation (for $48 \mathrm{~h}$ ). After that, the samples were subjected to a drying-wetting cycle. The drying and wetting branches of the retention curves were obtained by measuring the water content at different pressure heads.

One-step outflow experiment. Once the water retention curves were determined, at the end of wetting, and although the samples were saturated, the one-step outflow procedure began. A large negative pressure step, $h_{f}$, was suddenly applied at the bottom of the samples and the cumulative outflow volume was recorded with time until the water content reached the final equilibrium value, $\theta_{f}$. The $h_{f}$ value applied was equal to the highest negative pressure head used in the determination of the retention curve. The experimental one-step outflow procedure gave a series of measured outflow volumes, $V_{i}$, in the relevant times, $t_{i}$ $(i=1,2,3 \ldots N)$. The experimental data obtained were converted in mean values of water content $\bar{\theta}_{i}$, as $\overline{\theta_{i}}=\theta_{i n}-V_{i} / V_{o}$, where $\theta_{i n}$ is the uniform initial volumetric water content and $V_{o}$ is the sample volume.

Soil water diffusivity as a function of mean volumetric water content $[D(\bar{\theta})]$ was calculated from the one-step outflow data using the Valiantzas (1989) equation:
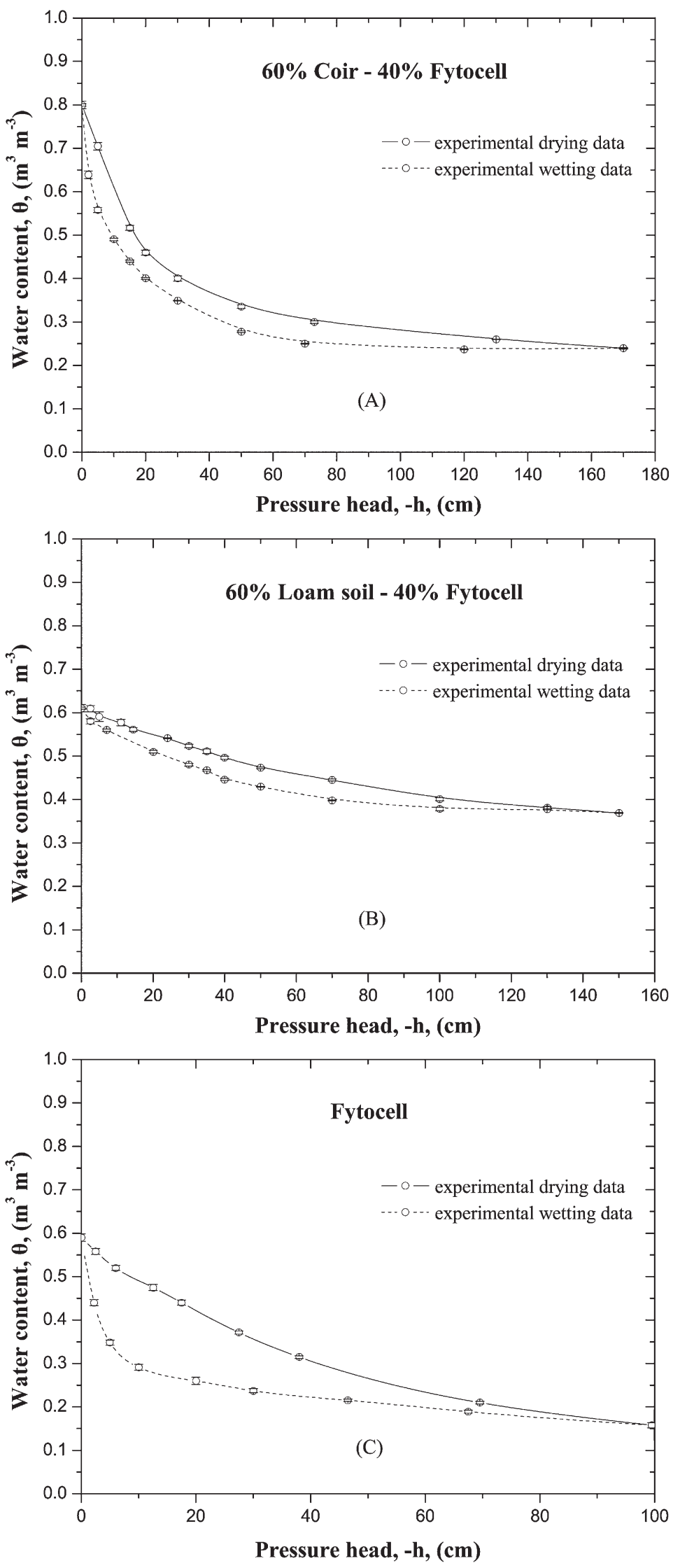

Fig. 2. Experimental water retention curves during drying and wetting for the substrates: 1) coir and Fytocell mixture at a proportion of $60 / 40(\mathrm{v} / \mathrm{v})$ coir/Fytocell $(\mathbf{A}) ; 2)$ loam soil and Fytocell mixture at a proportion of 60/40 (v/v) loam soil/Fytocell (B); and 3) Fytocell (C). Values are the means of three replications and bars represent $\pm \mathrm{SE}$. 

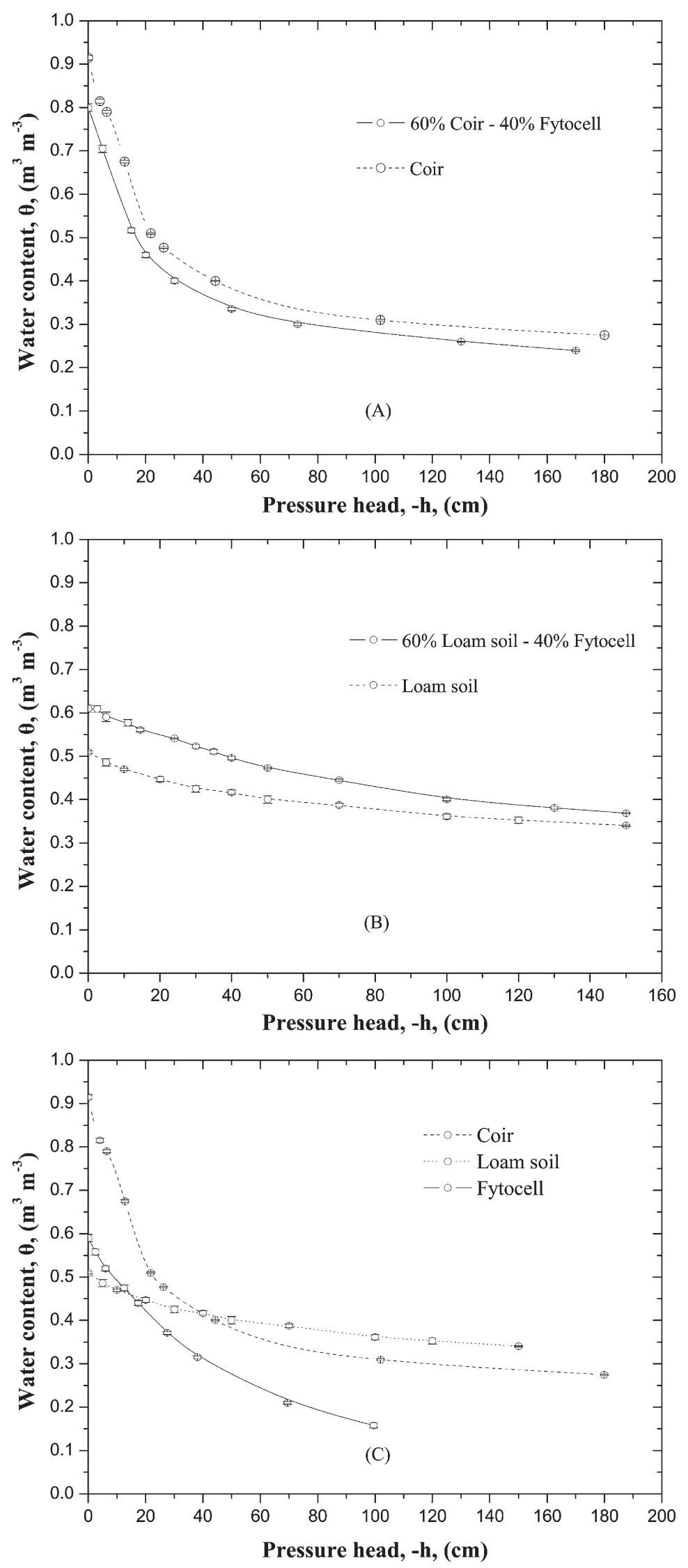

Fig. 3. Comparative presentation of the experimental water retention curves during drying among the substrates: 1) coir and its mixture with Fytocell at a proportion of $60 / 40(\mathrm{v} / \mathrm{v})$ coir/Fytocell (A); 2) loam soil and its mixture with Fytocell at a proportion of 60/40 (v/v) loam soil/Fytocell (B); and 3) loam soil, coir, and Fytocell $(\mathbf{C})$. Values are the means of three replications and bars represent $\pm \mathrm{SE}$.

$$
D(\bar{\theta})=-\frac{2 L^{2}}{\pi^{2}}\left(\frac{d q}{d \bar{\theta}}+\frac{q}{\bar{\theta}-\theta_{f}}\right)
$$

where $L$ is the length of the sample, $q$ is the rate of outflow $(q=d \bar{\theta} / d t)$, and $\theta_{f}$ is the final volumetric water content.

The proposed equation is validated for various types of soils (Valiantzas, 1989; Valiantzas and Sassalou, 1991) and substrates (Valiantzas et al., 2007).

From the plot of the measured cumulative outflow volume, $V$, against the square root of time, $\sqrt{t}$, the nonlinear portion of the curve (Stage III; Fig. 3), in which the effect of impedance of the porous plate becomes negligible, was identified (Passioura, 1976; Valiantzas, 1990). The derivatives $q=d \bar{\theta} / d t$ and $d q / d \bar{\theta}$ are calculated using a finite differences scheme from the outflow data $V_{i}\left(t_{i}\right)$ $(i=1,2 \ldots N)$ collected at this stage.

The three stages of outflow (Passioura, 1976) are clearly identifiable in all curves. In the first stage, corresponding to the initial part of the curve before the outflow becomes linear with $\sqrt{t}$, the plate impedance determines the outflow rate. In the second stage, during which the outflow varies linearly with $\sqrt{t}$, the effect of plate impedance is still significant. The third stage, corresponding to the portion of the curve where cumulative outflow ceases to be linear with $\sqrt{t}$, the effect of plate impedance is minimal.

Therefore, the overall procedure to determine $D(\bar{\theta})$ was:

1) Perform the one-step outflow experiment (as described previously) and record $V$ vs. $t$.

2) Plot $V$ vs. $\sqrt{t}$ and identify the portion of the curve where $V$ ceases to be linear with respect to $\sqrt{t}$ (Stage III).

3) Determine $D(\bar{\theta})$ function using Eq. [1].

Volumetric water content calculation. The $K(\theta)$ relationship was calculated using $K(\theta)=D(\bar{\theta}) d \theta / d h$ (Childs and Collis-George, 1950). The slope $d \theta / d h$ was calculated from the experimental water retention curves.

Saturated hydraulic conductivity. The $K_{s}$ was determined independently by the constanthead method (Klute and Dirksen, 1986). Each sample was subjected to a wetting-drying cycle before the measurement.

Estimation of volumetric water content using the van Genuchten-Mualem model. The hydraulic conductivity was calculated using the pore-size distribution model of Mualem (1976) combined with the Van Genuchten (1980) water retention function and was expressed as a function of the water content:

$$
\begin{aligned}
K= & K_{s} \cdot\left(\frac{\theta-\theta_{r}}{\theta_{s}-\theta_{r}}\right)^{1 / 2} \\
& \cdot\left[1-\left(1-\left(\frac{\theta-\theta_{r}}{\theta_{s}-\theta_{r}}\right)^{1 / m}\right)^{m}\right]^{2}
\end{aligned}
$$

where $\theta$ is the volumetric water content, $\theta_{s}$ and $\theta_{r}$ are the saturated and residual water 
content, respectively, $K_{s}$ is the saturated hydraulic conductivity, and $m$ is a fitting parameter, where $0<\mathrm{m}<1$.

Statistical analysis. Three replications per substrate were conducted for water retention curve, saturated and unsaturated hydraulic conductivity. The analysis of variance was performed using STATGRAPHICS Centurion XV statistical software (StatPoint, Inc., U.S.), and treatment means were compared using Tukey's honestly significant difference at a probability of $P=0.01$.

The goodness of fit of the $K(\theta)$ predictions obtained by the van Genuchten-Mualem model to the $K(\theta)$ predictions obtained from experimental outflow data using the Valiantzas (1989) equation was evaluated from the coefficient of determination $R^{2}$. The coefficient $R^{2}$ was calculated using the equation:

$$
R^{2}=1-\frac{\sum\left(\log \left(K^{E}\right)-\log \left(K^{P}\right)\right)^{2}}{\sum\left(\log \left(K^{E}\right)-\frac{\sum \log \left(K^{E}\right)}{N}\right)^{2}}
$$

where $K^{P}$ and $K^{E}$ are the hydraulic conductivity values obtained using the van Genuchten-Mualem model and the Valiantzas (1989) equation, respectively, and $N$ is the number of values.

\section{Results and Discussion}

The experimental drying and wetting branches of the water retention curves of Fytocell and its mixtures with coir and loam soil showed hysteresis for all the substrates studied (Fig. 2A-C). Hysteresis was most pronounced in the Fytocell (Fig. 2C). The maximum hysteretic difference (between drying and wetting curves having the same value of pressure head) relative to the value on the wetting curve is $\approx 68 \%$ for Fytocell (Fig. 2 C), $26 \%$ for coir/Fytocell (Fig. 2A), and $13 \%$ for loam soil/Fytocell (Fig. 2B).

The water retention curves of the substrates studied provide data for the range of pressure heads between 0 and $-170 \mathrm{~cm}$. The substrate properties provided from these retention curves, i.e., water retention capacity and air-water balance, highlight the importance of accounting for these properties when selecting plants for growing in the substrates studied and especially when plants are known to be sensitive to inadequate root aeration or anoxic root environments.
To assess the effect of Fytocell on hydraulic behavior of the coir/Fytocell and loam soil/ Fytocell mixtures, the retention curves of the latter were compared with those of pure coir and loam soil (Fig. 3A-B). The comparison showed that the addition of Fytocell in the 60 40 coir/Fytocell and 60/40 loam soil/Fytocell substrates led to the decrease (Fig. 3A) and increase (Fig. 3B) of the water retention capacity, respectively. Specifically, the total porosity (water content in $0-\mathrm{cm}$ pressure head) and the water contents at -50 and $-100 \mathrm{~cm}$ of the coir/Fytocell were significantly decreased by $0.117,0.056$, and $0.029 \mathrm{~m}^{3} \cdot \mathrm{m}^{-3}$, respectively, compared with the pure coir (Table 1). In contrast, comparing the loam soil/Fytocell with the pure loam soil, the total porosity and water contents at -50 and $-100 \mathrm{~cm}$ of the loam soil/Fytocell were significantly increased by $0.098,0.073$, and $0.040 \mathrm{~m}^{3} \cdot \mathrm{m}^{-3}$, respectively, compared with the pure loam soil (Table 1).

The easily available water (the amount of water released between -10 and $-50 \mathrm{~cm}$ ) and the air-filled porosity at $-50 \mathrm{~cm}$ for coir/ Fytocell were significantly decreased compared with pure coir (Table 1). Contrary, in the case of loam soil/Fytocell, these values were not significantly increased by the addition of Fytocell compared with loam soil (Table 1). Comparative presentation of the retention curves among the Fytocell, coir, and loam soil substrates (Fig. 3C) showed that the Fytocell has a lower total porosity and water retention capacity than the coir and higher total porosity and water retention capacity up to $\approx-20$-cm pressure head than the loam soil.

Overall, the addition of Fytocell had an opposite effect on the water retention capacity in the coir/Fytocell (Fig. 3A) than in loam soil/Fytocell (Fig. 3B) mixtures. This difference in hydraulic effect of Fytocell on the two substrates could be related to the water retention capacity of the Fytocell [it is higher than the loam soil (up to $-20 \mathrm{~cm}$ ) and lower than the coir] (Fig. 3C). It is also possible that there were differences in pore size distribution between the mixtures that resulted from structural differences between the Fytocell flakes and fibrous coir or granular loam soil.

The outflow data used to calculate $D(\theta)$ were collected from Stage III, which was identified from the nonlinear portion of the cumulative outflow volume vs. time (Fig. 4A-E).

The $K(\theta)$ values (Fig. 5A-C) indicated a rapid decrease in unsaturated hydraulic conductivity over a range of water contents, which are of vital importance to plant growth (De Boodt and Verdonck, 1972). The hydraulic conductivity of the 60/40 coir/Fytocell substrate decreased by approximately seven orders of magnitude, from $10.2\left(K_{s}\right)$ to $1.1 \times 10^{-6} \mathrm{~cm} \cdot \mathrm{min}^{-1}$ over a range of water contents varying between $80 \%$ and $25 \%$ (Fig. 5A), although for pure coir, the hydraulic conductivity values decreased from $7.8\left(K_{s}\right)$ to $1.3 \times 10^{-5} \mathrm{~cm} \cdot \mathrm{min}^{-1}$ (value shown in Fig. $6 \mathrm{~B}$ ) over a range of water contents varying between $92 \%$ and $40 \%$. In the case of $60 / 40$ loam soil/Fytocell, the decrease was approximately five orders of magnitude, from $0.34\left(K_{s}\right)$ to $8 \times 10^{-6} \mathrm{~cm} \cdot \mathrm{min}^{-1}$, for water contents between $61 \%$ and $39 \%$ (Fig. 5B), although for loam soil, the hydraulic conductivity values decreased from $0.5\left(K_{s}\right)$ to $1.5 \times 10^{-5} \mathrm{~cm} \cdot \mathrm{min}^{-1}$ (value shown in Fig. 6A) over a range of water contents varying between $51 \%$ and $36 \%$. Also, the hydraulic conductivity of the Fytocell decreased by approximately five orders of magnitude, from $3.17\left(K_{s}\right)$ to $9.5 \times 10^{-5} \mathrm{~cm} \cdot \mathrm{min}^{-1}$ over a range of water contents varying between and 59\% and 20\%, (Fig. 5C).

Saturated hydraulic conductivity values were high for all substrates examined (Table 1). The addition of Fytocell in the 60/40 coir/ Fytocell increased significantly the saturated hydraulic conductivity compared with pure coir. On the other hand, the saturated hydraulic conductivity of the 60/40 loam soil/Fytocell was not significantly decreased by the addition of Fytocell compared with loam soil (Table 1).

Furthermore, the unsaturated hydraulic conductivity values of Fytocell (Fig. 5C) were the greatest for water contents lower than $0.40 \mathrm{~m}^{3} \cdot \mathrm{m}^{-3}$ compared with the coir/Fytocell (Fig. 5A) and loam soil/Fytocell (Fig. 5B) mixtures. This is of fundamental importance; because the rate of evapotranspiration is directly correlated to hydraulic conductivity, the water flow rate of Fytocell has a great capacity to replace water loss caused by evapotranspiration. This should be taken into account to create growing mixtures based on Fytocell according to crop needs. The comparison of the two mixtures with Fytocell showed that the 60/ $40 \mathrm{coir} /$ Fytocell mixture has a greater capacity $(\approx 40$-fold) of replacing water losses caused by evapotranspiration than the 60/40 loam soil/Fytocell mixture (Fig. 5A-B).

In addition, the $K(\theta)$ values obtained from the experimental outflow data using the

Table 1. Physical-hydraulic characteristics of the substrates: 1) coir; 2) coir and Fytocell mixture at a proportion of 60/40 (v/v) coir/Fytocell; 3) loam soil; 4) loam soil and Fytocell mixture at a proportion of $60 / 40(\mathrm{v} / \mathrm{v})$ loam soil/Fytocell; and 5) Fytocell. ${ }^{\mathrm{z}}$

\begin{tabular}{|c|c|c|c|c|c|c|}
\hline Substrate & $\begin{array}{l}\text { Total porosity } \\
\left(\mathrm{m}^{3} \cdot \mathrm{m}^{-3}\right)\end{array}$ & $\begin{array}{l}\text { Water content at } \\
-50 \mathrm{~cm}\left(\mathrm{~m}^{3} \cdot \mathrm{m}^{-3}\right)\end{array}$ & $\begin{array}{l}\text { Water content at } \\
-100 \mathrm{~cm}\left(\mathrm{~m}^{3} \cdot \mathrm{m}^{-3}\right)\end{array}$ & $\begin{array}{l}\text { Easily available } \\
\text { water }^{\mathrm{x}}\left(\mathrm{m}^{3} \cdot \mathrm{m}^{-3}\right)\end{array}$ & $\begin{array}{l}\text { Air-filled porosity at } \\
-50 \mathrm{~cm}\left(\mathrm{~m}^{3} \cdot \mathrm{m}^{-3}\right)\end{array}$ & $\begin{array}{c}K_{s}{ }^{\mathrm{w}} \\
\left(\mathrm{cm} \cdot \mathrm{min}^{-1}\right)\end{array}$ \\
\hline 60/40 coir/Fytocell & $0.801 \mathrm{~b}$ & $0.335 \mathrm{c}$ & $0.281 \mathrm{~d}$ & $0.276 \mathrm{~b}$ & $0.466 \mathrm{~b}$ & $10.2 \mathrm{a}$ \\
\hline Loam soil & $0.510 \mathrm{~d}$ & $0.400 \mathrm{~b}$ & $0.361 \mathrm{~b}$ & $0.070 \mathrm{~d}$ & $0.110 \mathrm{~d}$ & $0.50 \mathrm{~d}$ \\
\hline Fytocell & $0.592 \mathrm{c}$ & $0.275 \mathrm{~d}$ & $0.158 \mathrm{e}$ & $0.217 \mathrm{c}$ & $0.316 \mathrm{c}$ & $3.17 \mathrm{c}$ \\
\hline
\end{tabular}

${ }^{\mathrm{z}}$ Values are the means of three replications $(\mathrm{n}=3)$. Means that differ significantly using Tukey's honestly significant difference at a probability level of 0.01 are noted with different letters.

${ }^{\mathrm{y}}$ The water content at $0 \mathrm{~cm}$ pressure head (saturation).

${ }^{\mathrm{x}}$ The amount of water released between pressure heads of -10 and $-50 \mathrm{~cm}$.

${ }^{\text {w}}$ The value of hydraulic conductivity at saturation. 

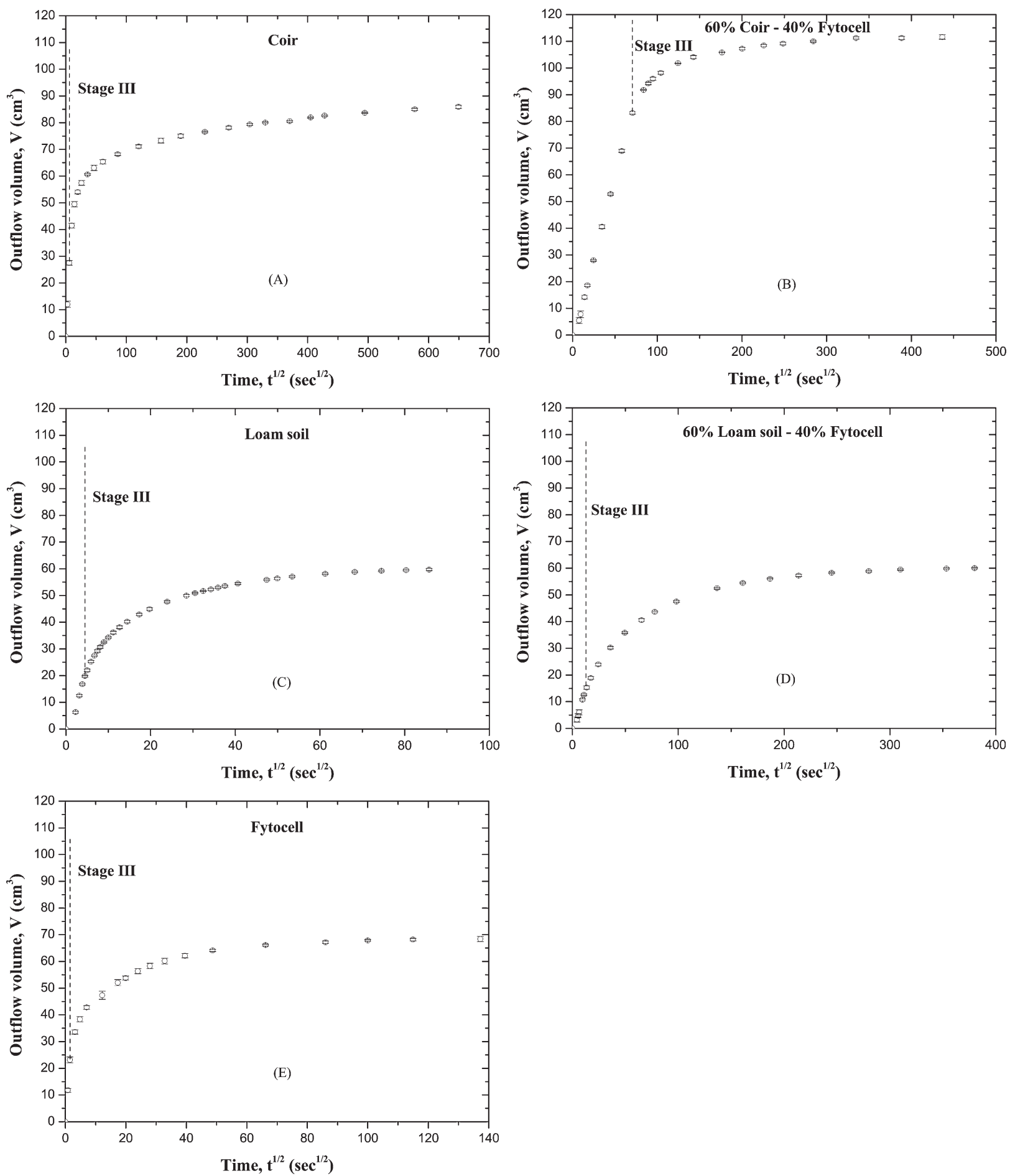

Fig. 4. Cumulative outflow volume against the square root of time and presentation of Stage III, in which the effect of porous plate impedance becomes negligible, from one-step outflow experiments, for the substrates: 1) coir (A); 2) coir and Fytocell mixture at a proportion of 60/40 (v/v) coir/Fytocell (B); 3 ) loam soil (C); 4) loam soil and Fytocell mixture at a proportion of $60 / 40$ (v/v) loam soil/Fytocell (D); and 5) Fytocell (E). Values are the means of three replications and bars represent $\pm \mathrm{SE}$.

Valiantzas (1989) equation were compared with the $K(\theta)$ predictions obtained by the van Genuchten-Mualem model using as input data the experimental water retention data and the $K_{s}$ value (Fig. 5A-C). The van GenuchtenMualem model parameters, $m$ and $\theta_{r}$, and the correlation coefficient $R^{2}$ of the fitted curve are given in Table 2. The comparison indicated that there is a satisfactory agreement of the results $\left(0.937 \leq R^{2} \leq 0.996\right)$ and showed the flexibility of the van Genuchten-Mualem model describing the relationship between unsaturated hydraulic conductivity and water content (Fig. 5A-C).

To assess the effect of the Fytocell addition in the alteration of the unsaturated hydraulic conductivity of its mixtures, the $K(\theta)$ relations of the $60 / 40$ coir/Fytocell and $60 / 40$ loam soil/Fytocell were compared with those of pure coir and loam soil (Fig. 6A-B).
The addition of $40 \%$ Fytocell in the loam soil contributed to a significant reduction of the unsaturated hydraulic conductivity values compared with loam soil for a range of water contents, which are critical for plant growth (the difference between $K$ values at $0.40 \mathrm{~m}^{3} \cdot \mathrm{m}^{-3}$ water content is $\approx 10$-fold) (Fig. $6 \mathrm{~A}$ ). In contrast, the $40 \%$ Fytocell addition in the coir substrate significantly improved the $K$ values compared with pure coir (the difference 

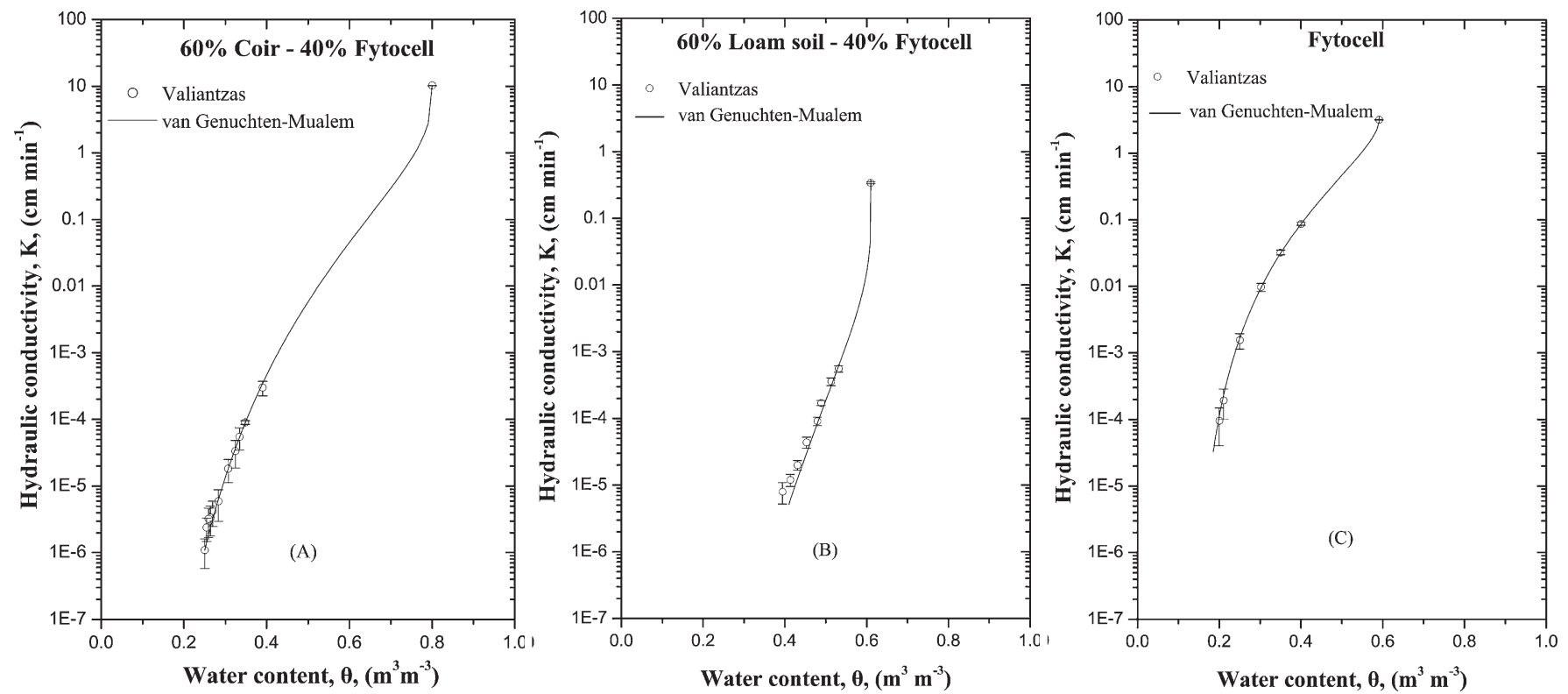

Fig. 5. Hydraulic conductivity as a function of water content for the substrates: 1) coir and its mixture with Fytocell at a proportion of 60/40 (v/v) coir/Fytocell (A); 2) 60/40 (v/v) loam soil/Fytocell (B); and 3) Fytocell (C) obtained using outflow data and the Valiantzas equation and the van Genuchten-Mualem model. Values are the means of three replications and bars represent \pm SE.
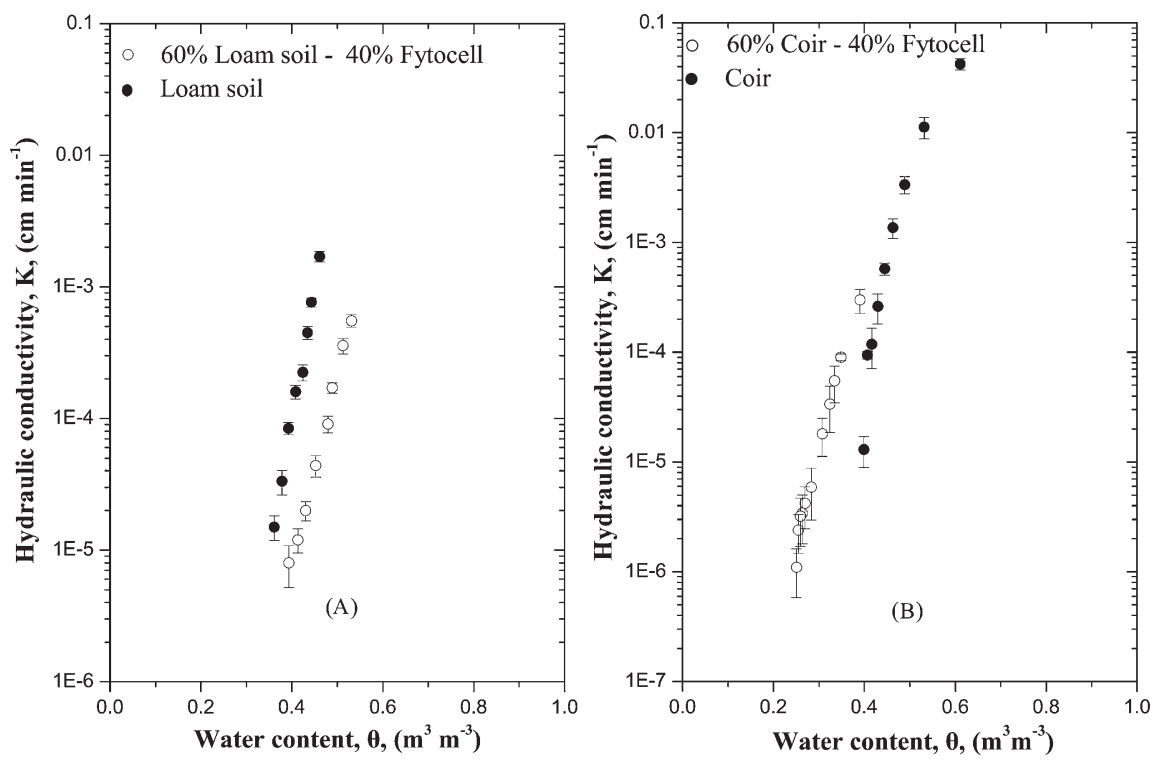

Fig. 6. Comparative presentation of the hydraulic conductivity as a function of water content, obtained using outflow data and the Valiantzas equation, among the substrates: 1) loam soil and its mixture with Fytocell at a proportion of 60/40 (v/v) loam soil/Fytocell (A); and 2) coir and its mixture with Fytocell at a proportion of $60 / 40(\mathrm{v} / \mathrm{v})$ coir/Fytocell $(\mathbf{B})$. Values are means of three replications and bars represent \pm SE.

Table 2. van Genuchten-Mualem model parameters of $K(\theta)$ fitting parameter $(\mathrm{m})$ and residual volumetric water content $\left(\theta_{r}\right)^{z}$

\begin{tabular}{llll}
\hline Substrate & $\mathrm{m}$ & $\theta_{r}\left(\mathrm{~m}^{3} \cdot \mathrm{m}^{-3}\right)$ & $R^{2}$ \\
\hline 60/40 coir/Fytocell & 0.251 & 0.105 & 0.996 \\
60/40 loam soil/Fytocell & 0.119 & 0.00 & 0.937 \\
Fytocell & 0.507 & 0.138 & 0.994 \\
\hline z &
\end{tabular}

${ }^{\mathrm{z}} R^{2}$ is the coefficient of determination of the $K(\theta)$ fitted curves of the substrates: 1) coir and Fytocell mixture at a proportion of $60 / 40 \mathrm{coir} /$ Fytocell (v/v);2) loam soil and Fytocell mixture at a proportion of 60/40 loam soil/Fytocell (v/v); and 3) Fytocell. between $K$ values at $0.40 \mathrm{~m}^{3} \cdot \mathrm{m}^{-3}$ water content is $\approx 30$-fold) (Fig. $6 \mathrm{~B}$ ) classifying the $60 / 40$ coir/Fytocell mixture as the most suitable substrate to meet plant water demand during periods of high evapotranspiration. These results are in line with the water retention curve observations.

To conclude, addition of $40 \%$ Fytocell to an organic coir substrate decreased water retention capacity and increased saturated and unsaturated hydraulic conductivity compared with $100 \%$ coir. In contrast, addition of $40 \%$
Fytocell to an inorganic loam soil increased water retention capacity and decreased saturated and unsaturated hydraulic conductivity compared with $100 \%$ loam soil. Moreover, the comparison of $K(\theta)$ values between coir and loam soil mixtures with Fytocell showed that the $60 / 40 \mathrm{coir} /$ Fytocell substrate is more suitable than the $60 / 40$ loam soil/Fytocell to meet plant water demands during periods of high evapotranspiration.

\section{Literature Cited}

Baader, P. 1999. Fytogreen-foam in laying out sport fields. 1st Fytogreen Seminar, 2-3 Dec., Beneden Leeuwen, The Netherlands.

Chan, C.L. and D.C. Joyce. 2007. Effects of urea formaldehyde resin foam soil amendment on growth and response to transient water deficit stress of potted Flindersia schottiana saplings. Sci. Hort. 114:112-120.

Childs, E.C. and N. Collis-George. 1950. The permeability of porous materials. Proc. R. Soc. Lond. 201A:392-405.

De Boodt, M. and O. Verdonck. 1972. The physical properties of the substrates in horticulture. Acta Hort. 26:37-44.

Fonteno, W.C., D.K. Cassel, and R.A. Larson. 1981. Physical properties of three container media and their effect on Poinsettia growth. J. Amer. Soc. Hort. Sci. 106:736-741.

Gardner, W.R. 1962. Note on the separation and solution of diffusion type equations. Soil Sci. Soc. Am. Proc. 26:404.

Gupta, S.C., D.A. Farrel, and W.E. Larson. 1974. Determining effective soil water diffusivities from one-step outflow experiments. Soil Sci. Soc. Amer. J. 38:710-716.

Haines, W.B. 1930. Studies in the physical properties of soils. V. The hysteresis effect in capillary properties and the modes of moisture distribution associated therewith. J. Agr. Sci. 20:97-116.

Karlovich, P.T. and W.C. Fonteno. 1986. The effect of soil moisture tension and volume moisture on the growth of chrysanthemum in three container media. J. Amer. Soc. Hort. Sci. 111:191-195. 
Klute, A. and C. Dirksen. 1986. Hydraulic conductivity and diffusivity: Laboratory methods, $\mathrm{p}$. 687-734. In: Klute, A. (ed.). Methods of soil analysis: Part 1, physical and mineralogical methods. American Society of Agronomy, Madison, WI.

Londra, P.A. 2001. Moisture-aeration balance of substrates as developed under different irrigation treatments. PhD thesis, Agricultural University of Athens, Dept. of Natural Resources Management and Agricultural Engineering, Athens, Greece.

Londra, P.A. 2010. Simultaneous determination of water retention curve and unsaturated hydraulic conductivity of substrates using a steady-state laboratory method. HortScience 45:1106-1112.

Londra, P.A. and J.D. Valiantzas. 2011. Soil water diffusivity determination using a new twopoint outflow method. Soil Sci. Soc. Amer. J. 75:1343-1346.

Milks, R.R., W.C. Fonteno, and R. Larson. 1989. Hydrology of horticultural substrates: I. Mathematical models for moisture characteristics of horticultural container media. J. Amer. Soc. Hort. Sci. 144:48-52.

Mooney, S. and S. Baker. 1999. The effects of fytogreen foam on the soil physical properties of sand-dominated root zones for sports turf: A laboratory study. Document No. 0066/3. The Sports Turf Research Institute (STRI). p. 17.
Mualem, Y. 1976. A new model for predicting the hydraulic conductivity of unsaturated porous media. Water Resour. Res. 12:513-522.

Nektarios, P.A., A.E. Nikolopoulou, and I. Chronopoulos. 2004. Sod establishment and turfgrass growth as affected by urea-formaldehyde resin foam soil amendment. Sci. Hort. 100:203-213.

Nektarios, P.A., P. Tsiotsiopoulou, and I. Chronopoulos 2003. Soil amendments reduce roof garden weight and influence the growth rate of Lantana. HortScience 38:618-622.

Nguyen, T.-T., D.C. Joyce, and S.-Q. Dinh. 2009. Effects of artificial amendments in potting media on Orthosiphon aristatus growth and development. Sci. Hort. 123:129-136.

Nikolopoulou, A.E. and P.A. Nektarios. 2004. Effects of resin foam soil amendment on the growth of turfgrass subjected to different compaction levels. Acta Hort. 661:177-181.

Nikolopoulou, A.E., G. Tsoggarakis, D. Gourlias, and P.A. Nektarios. 2004. Effects of fertilisers and foam soil amendment on sod establishment. Acta Hort. 661:265-270.

Passioura, J.B. 1976. Determining soil water diffusivities from one step outflow experiments. Aust. J. Soil Res. 15:1-8

Valiantzas, J.D. 1989. A simple approximate equation to calculate diffusivities from one-step outflow experiments. Soil Sci. Soc. Amer. J. $53: 342-349$.
Valiantzas, J.D. 1990. Analysis of outflow experiments subject to significant plate impedance. Water Resour. Res. 26:2921-2929.

Valiantzas, J.D., P.G. Kerkides, and A. Poulovassilis. 1988. An improvement to the one-step outflow method for the determination of soil water diffusivities. Water Resour. Res. 24:19111920.

Valiantzas, J.D., P.A. Londra, and A. Sassalou. 2007. Explicit formulae for the soil water diffusivity using the one-step outflow technique. Soil Sci. Soc. Amer. J. 71:1685-1693.

Valiantzas, J.D. and A. Sassalou. 1991. Laboratory determination of unsaturated hydraulic conductivity using a generalized-form hydraulic model. J. Hydrol. 128:293-304.

Van Genuchten, M.Th. 1980. A closed-form equation for predicting the hydraulic conductivity of unsaturated soils. Soil Sci. Soc. Amer. J. 44:892-898.

Wallach, R., F.F. da Silva, and Y. Chen. 1992. Unsaturated hydraulic characteristics of composted agricultural wastes, tuff and their mixtures. Soil Sci. 153:434-441.

Welleman, J.C.C. 2005. Fytocell, an increasingly popular substrate. Acta Hort. 697:195-198.

Werminghausen, B. 1972. The application of synthetic media in plant propagation. III Symposium on Peat in Horticulture, Dublin Ireland. Acta Hort. 26:159-164. 